\title{
Total Maxillary Reconstruction Using a Double- Barreled and Double Skin Paddle Fibular Flap after Total Maxillectomy
}

\author{
Miguel de la Parra, Gerardo Sanchez, Jaime Lopez, Adrian Perez, Norberto Naal \\ Department of Plastic and Reconstructive Surgery, Mexican Institute of Social Security Monterrey, NL, Mexico
}

Chondroblastomas are rare entities accounting for approximately $1 \%$ of all primary bone tumors. We describe a case of a 7-year-old girl with a giant chondroblastoma of the maxilla, treated with bilateral class III maxillectomy and reconstruction with a double-barreled and double skin paddle fibular free flap. We show evidence of an excellent aesthetic outcome at 6 months' follow up with no evidence of tumor recurrence.

Keywords Fibula / Maxilla / Surgical flap
Correspondence: Miguel de la Parra Department of Plastic and Reconstructive Surgery,

Mexican Institute of Social Security, Hidalgo 2480 Pte. Obispado, c.p. 64060, Cons. 212, Monterrey N.L., Mexico

Tel: $+81-81518452$

Fax: +81-83338844

E-mail:drdelaparra@yahoo.com.mx

No potential conflict of interest relevant to this article was reported.

\section{INTRODUCTION}

Reconstruction of the maxilla with the fibular free flap is a popular and well-described technique. This flap provides a well vascularized piece of bone that can be easily used to fill any defect of the maxilla or mandibula with a skin paddle as a mucosal substitute [1-3]. There have been many reports of its use in mandibular reconstruction since it was first described by Hidalgo [3] in 1989.

Its use in maxillary reconstruction has been established as a simple bone or double-barreled flap and a simple or double skin paddle flap [4-6].

\section{CASE}

We present the case of a 12-year-old girl with a large mass in the maxilla that had grown for the previous six months, was diagnosed as chondroblastoma, and was treated with bilateral class IIIc maxillectomy [7] (high maxillectomy) and reconstruction with a double-barreled and double perforator-based skin paddle fibula flap (Fig. 1).

\section{Surgical technique}

In the supine position, starting with the scanning of the two perforator vessels from the peroneal artery, an incision was made along the edge of the fibula and dissection was performed from the flexor hallucis longus and brevis down to the periosteum, preserving the two skin paddles with a perforator vessel in each one.

Simultaneously, a bilateral class III maxillectomy was carried out, removing the maxilla by performing a Lefort I type osteotomy. The tumor measured $10 \mathrm{~cm} \times 12 \mathrm{~cm}$, covering the entire

Copyright () 2013 The Korean Society of Plastic and Reconstructive Surgeons

This is an Open Access article distributed under the terms of the Creative Commons Attribution Non-Commercial License (http://creativecommons.org/

licenses/by-nc/3.0/) which permits unrestricted non-commercial use, distribution, and reproduction in any medium, provided the original work is properly cited.

www.e-aps.org 


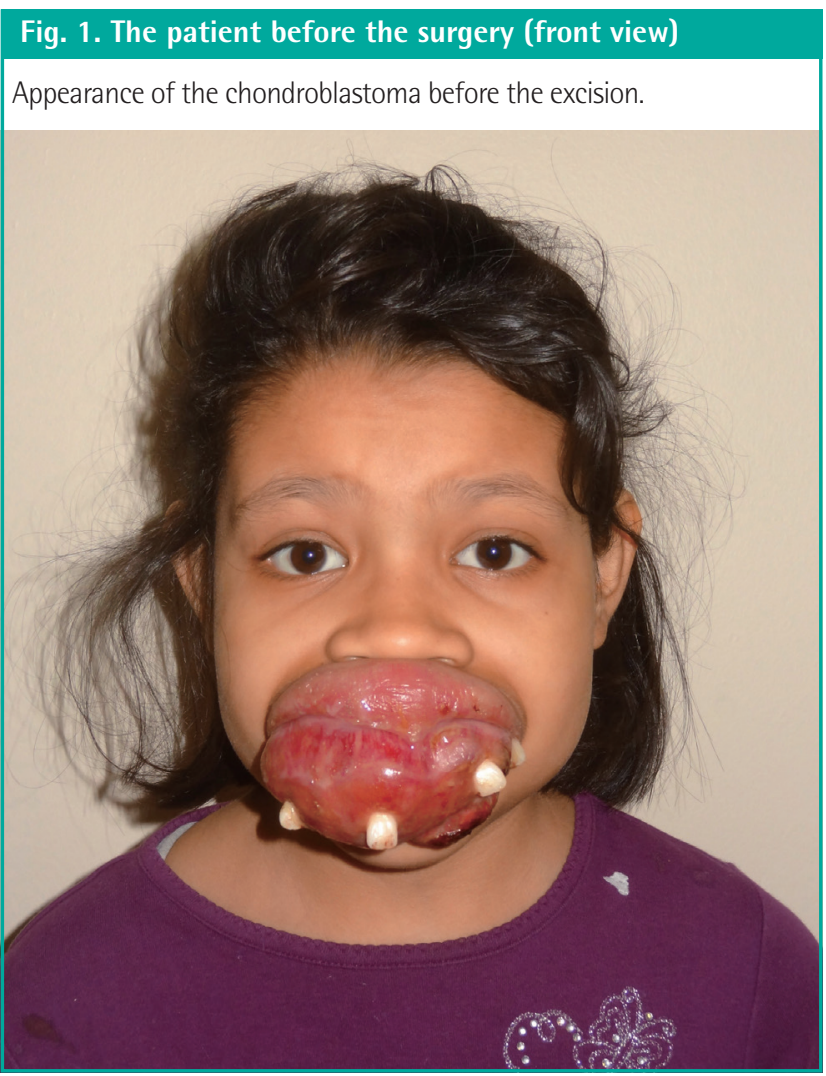

Fig. 2. Maxillectomy with the completely resected tumor

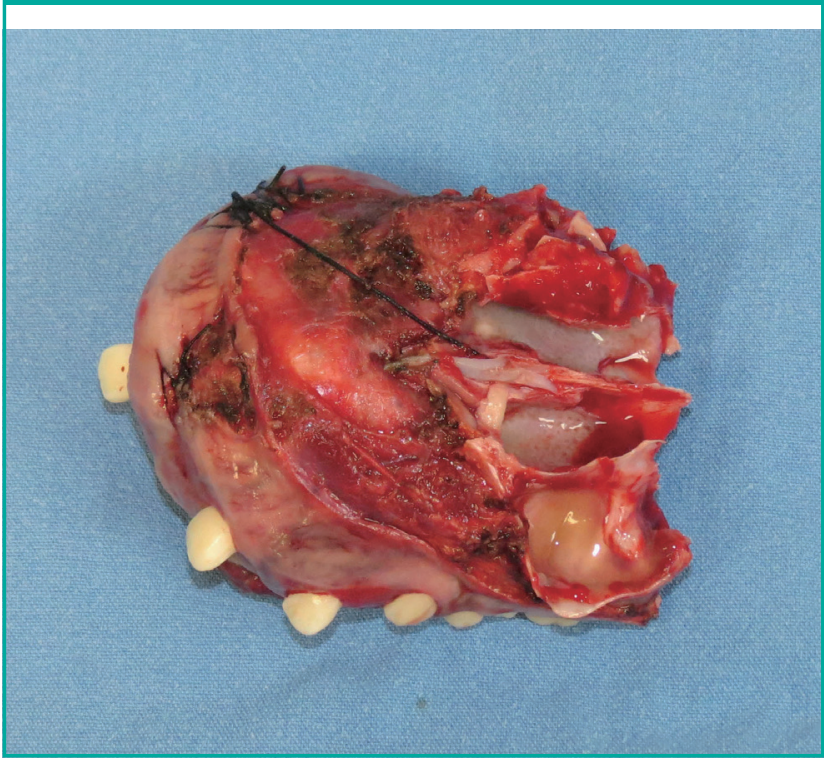

floor of the maxilla, from the soft palate at the back to the upper lip in the front, affecting the vomer and the nasal floor (Fig. 2).

The fibula was sectioned into two pieces with one skin paddle in each one, preserving the peroneal artery as the principal pedicle. Both segments were fixed "in situ" with screws, and subsequently the pedicle was sectioned at the proximal end. Each end of the bone was fixed to the ascending ramus of the maxilla with a 2.0-mm mini-plate titanium system (Figs. 3, 4).

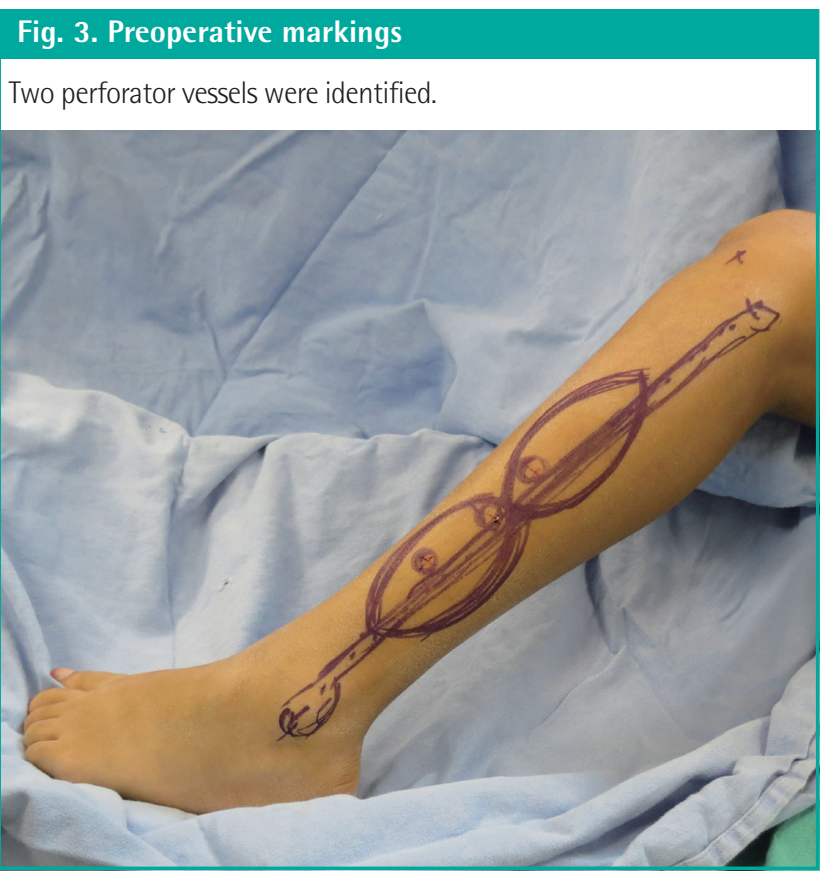

Fig. 4. The flap finished "in situ"

The double-barreled and double skin paddle flap can be seen.

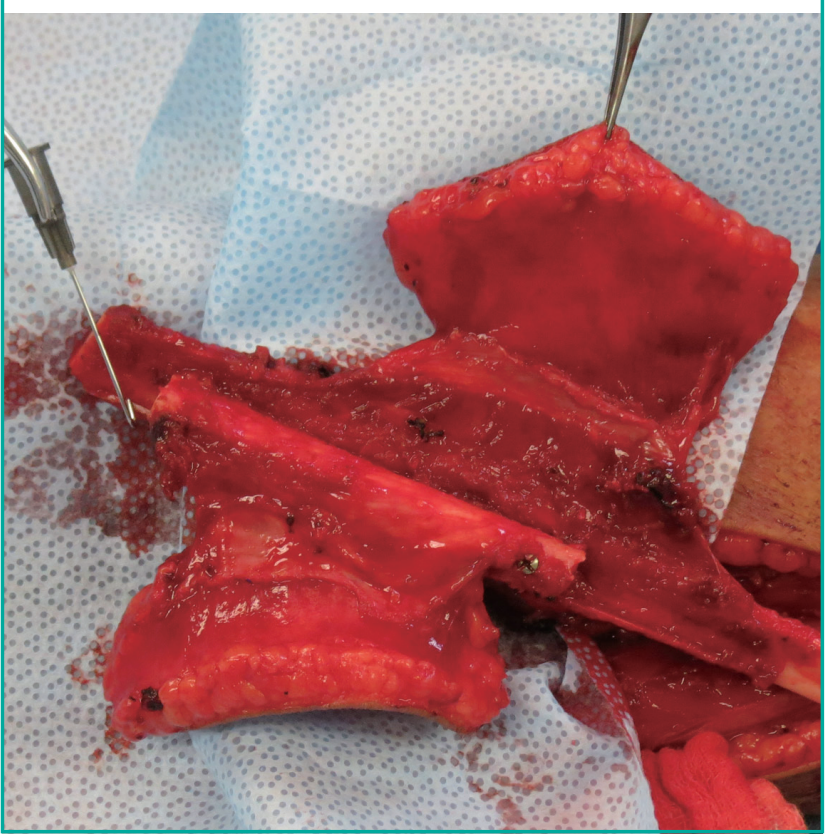

The superior skin paddle was deepithelized in the central zone and sutured to the mucosa of the nasal septum. The lateral edge of the superior skin paddle was sutured to the lateral wall of the nasal mucosa at the level of the piriform aperture to make a place for the nasal floor. The inferior skin paddle was sutured to the soft palate in the posterior edge and to the labial mucosa at the anterior end. The anastomosis of the artery and the vein were made using a saphenous vein graft from the facial to the peroneal vessels passing through the cheek, using simple stitch- 


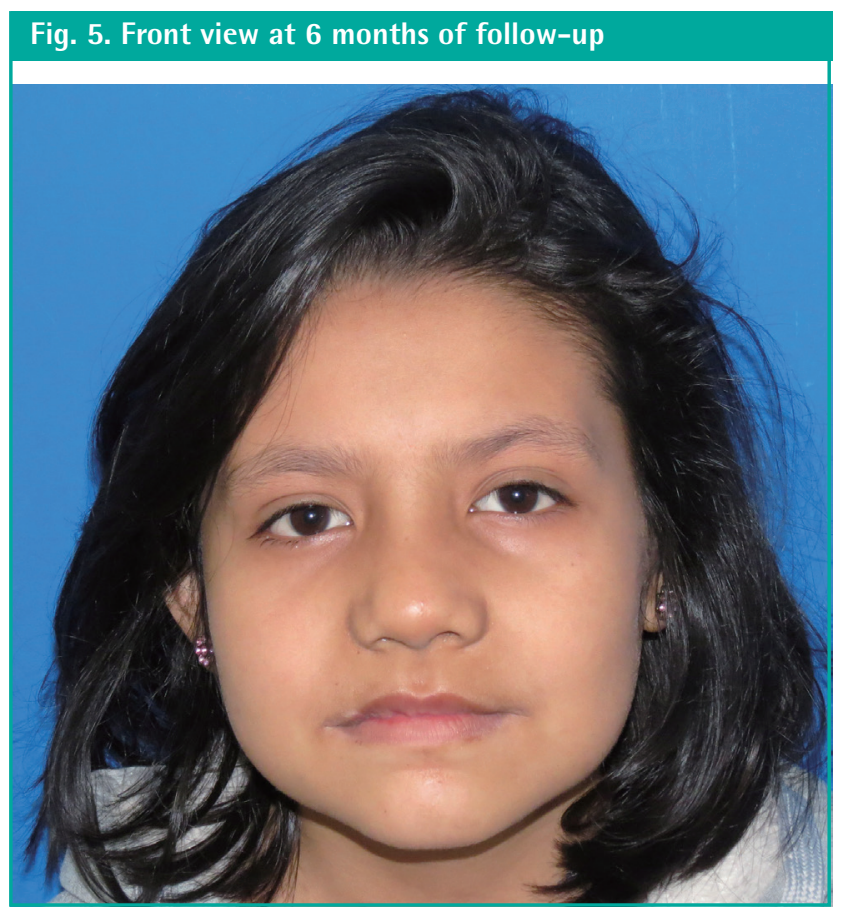

Fig. 6. Postoperative tomography with three-dimensional reconstruction

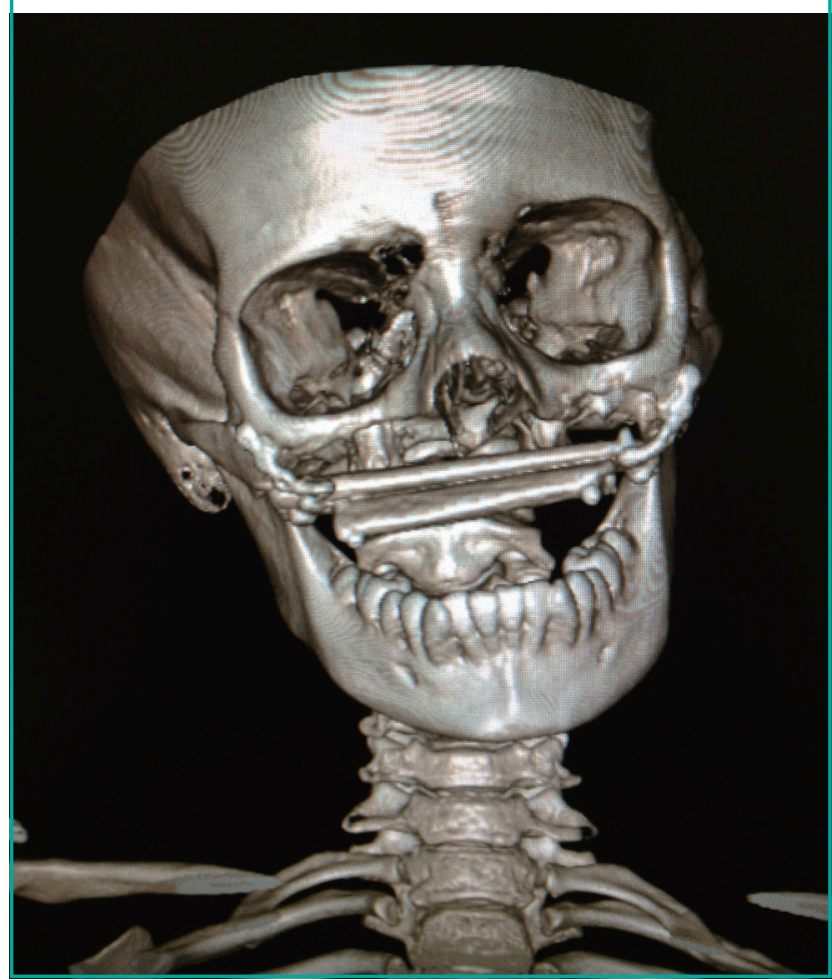

es with 9-0 nylon.

The follow-up period was 6 months, and there was no evidence of tumor recurrence. The functional results were excellent with a well-tolerated liquid and soft diet. The patient's speech is satisfactory overall; however, her consonants are slurred. The
Fig. 7. Histopathological study $(\mathrm{H} \& \mathrm{E}, \times 400) \times$

Small clear core polyhedral tumor cells without atypical mitosis and some giant cells.

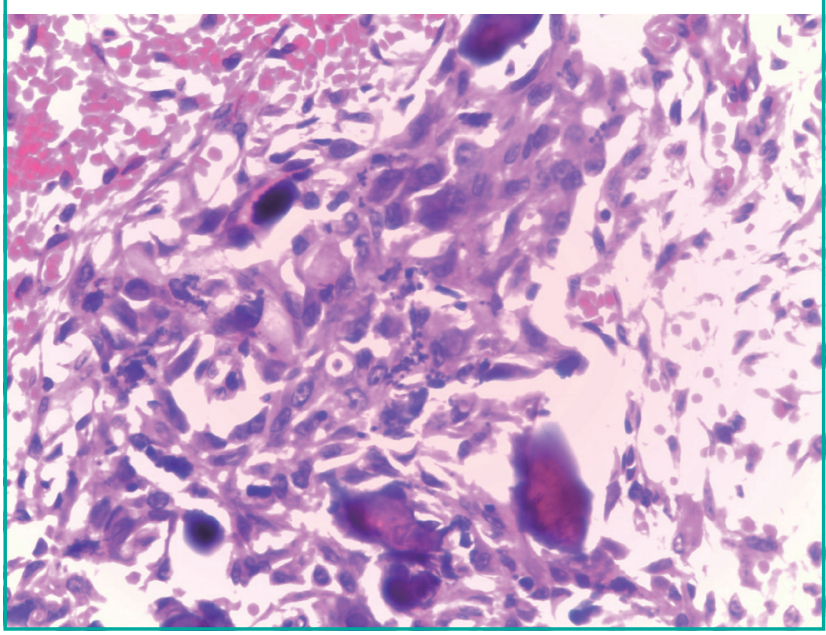

histological study reported a solid tumor well defined by a pseudo-capsule, limited by the gingival mucosa. Small polyhedral tumor cells were found with scattered osteoclastic giant cells with no atypical mitosis. The diagnosis was chondroblastoma (Figs. 5-7).

\section{DISCUSSION}

Chondroblastoma of the bone is a benign tumor that has wellcharacterized radiographic and histologic features. It tends to affect the epiphyseal ends of long bones in men during the second and third decades of life. The tumor is located more frequently at other sites in older patients.

Treatment methods fall into a broad spectrum, ranging from conservative medical therapies to a variety of surgical procedures, which may or may not employ the use of local adjuvant treatment or bone grafting when the defect is small, to free vascular bone flaps for larger defects. These flaps could be fibular or osteofasciocutaneous radial forearm flaps. In this case, we used the entire fibula in the flap because of the need to obtain a large amount of bone. A radial or iliac crest bone flap would not have been appropriate in this case.

The chondroblastoma localized in the maxilla is an uncommon entity. Only a few cases have been reported in the literature [8]. The most important goal of oncological surgery is the complete resection of the tumor. Although chondroblastomalike lesions are a benign kind of tumor, the biologic behavior is difficult to evaluate histopathologically, and it is not easy to distinguish them from other bone tumors, fibro-osseous lesions, and odontogenic neoplasms on the basis of integrated clinical, radiologic, and histologic features. They also usually manifest an 
indolent clinical course [9].

The reconstruction of the maxilla with the fibular free flap has been well described. There are some variations in the surgical technique for this flap, such as the double-barreled, double skin paddle, and most recently, the prelaminated osteomucosal fibula flap [4-6].

In invasive tumors of the maxilla, such as this case, is imperative to perform wide resection with complex reconstruction of the bone and soft tissue. Worldwide, the fibular free flap is the most used for this purpose because of its versatility for the reconstruction of large osseous defects. The bone supports osseointegrated implants, and the soft tissue can be included for intraoral or extraoral mucosa or skin supply.

We described a complex case of reconstruction; because of the invasive nature of the tumor, a total maxillectomy was required. A double-barreled fibular flap was used to provide more projection to the maxilla and two skin paddles: the inferior one for the top of the hard palate and the superior for the bottom of the nasal floor.

In conclusion, the double-barreled double perforator-based skin paddle fibular free flap is a good option for total maxillectomy reconstruction, as it provides good projection and skin covering for the nasal floor and the hard palate.

\section{REFERENCES}

1. Santamaria E, Cordeiro PG. Reconstruction of maxillec- tomy and midfacial defects with free tissue transfer. J Surg Oncol 2006;94:522-31.

2. Rodriguez ED, Martin M, Bluebond-Langner R, et al. Microsurgical reconstruction of posttraumatic high-energy maxillary defects: establishing the effectiveness of early reconstruction. Plast Reconstr Surg 2007; 120:103S-17S.

3. Hidalgo DA. Fibula free flap: a new method of mandible reconstruction. Plast Reconstr Surg 1989;84:71-9.

4. Ulkur E, Karagoz H, Kulahci Y, et al. One-and-a-half-barrel vascularized free fibular flap for the reconstruction of segmental mandibular defect. J Craniofac Surg 2013;24:e167-9.

5. Peng X, Mao C, Yu GY, et al. Maxillary reconstruction with the free fibula flap. Plast Reconstr Surg 2005; 115:1562-9.

6. Santamaria E, Correa S, Bluebond-Langner R, et al. A shift from the osteocutaneous fibula flap to the prelaminated osteomucosal fibula flap for maxillary reconstruction. Plast Reconstr Surg 2012;130:1023-30.

7. Brown JS, Rogers SN, McNally DN, et al. A modified classification for the maxillectomy defect. Head Neck 2000; 22:17-26.

8. Al-Dewachi HS, Al-Naib N, Sangal BC. Benign chondroblastoma of the maxilla: a case report and review of chondroblastomas in cranial bones. Br J Oral Surg 1980;18:150-6.

9. Turcotte RE, Kurt AM, Sim FH, et al. Chondroblastoma. Hum Pathol 1993;24:944-9. 